\title{
Reducing inappropriate prescribing easier said than done
}

\author{
Cite as: CMAJ 2017 May 15;189:E706-7. doi: 10.1503/cmaj.1095427
}

aws are changed, lucrative incentives offered, patients are cut off. Sometimes the right combination of these and other policy measures will have the desired result in curtailing inappropriate prescribing. At other times, like the drugs being curtailed, there are unintended adverse consequences.

The stakes are high. In 2013, publicly funded drug plans in Canada spent an estimated \$419 million on inappropriate prescriptions and $\$ 1.4$ billion on indirect health care costs, according to a study by Steven Morgan and colleagues published in CMAJ Open on June 22, 2016.

"What the hell are we doing wrong?" asked pharmacist Justin Turner, at an Apr. 24 session during the 2017 Canadian Agency for Drugs and Technologies in Health Symposium. "Why can't we address these? Why can't we learn from each other? How do we break down the silos?"

Inappropriate prescribing is where the harm of the drug outweighs the benefit. "Sometimes we start a drug with the best of intentions, but as the patient ages and we get more comorbidities, the riskbenefit can change," said Turner, an assistant director with the year-old Canadian Deprescribing Network (CaDeN). "Effective policy will allow us as clinicians to focus on our clinical goals, but at the same time, fulfill the policy goals of reducing costs, reducing harm and improving care."

CaDeN uses a different approach to examine evidence called active realist reviews. Whereas systematic reviews assess academic research, realist reviews also look at what works for whom and under what circumstances. It goes beyond the literature to include discussions with stakeholders and expert groups, and the grey literature, said panelist Jay Shaw, a scientist at the Women's College Hospital Institute for Health System Solutions and Virtual Care.

As a case in point, the three panelists focused on benzodiazapines (BZD).

Inappropriate use of BZD greatly increases the risk of falls, especially in older people, as well as fractures, hospitalization, mortality and motor vehicle accidents. A recent study in CMAJ found that BZD increased risk of pneumonia in community-dwelling adults with dementia. In Canada, $13 \%$ of community-dwelling seniors are on BZD, as a cost of $\$ 92$ million to taxpayers.

Public policy can help mitigate these harms. In Denmark, rules were imple-

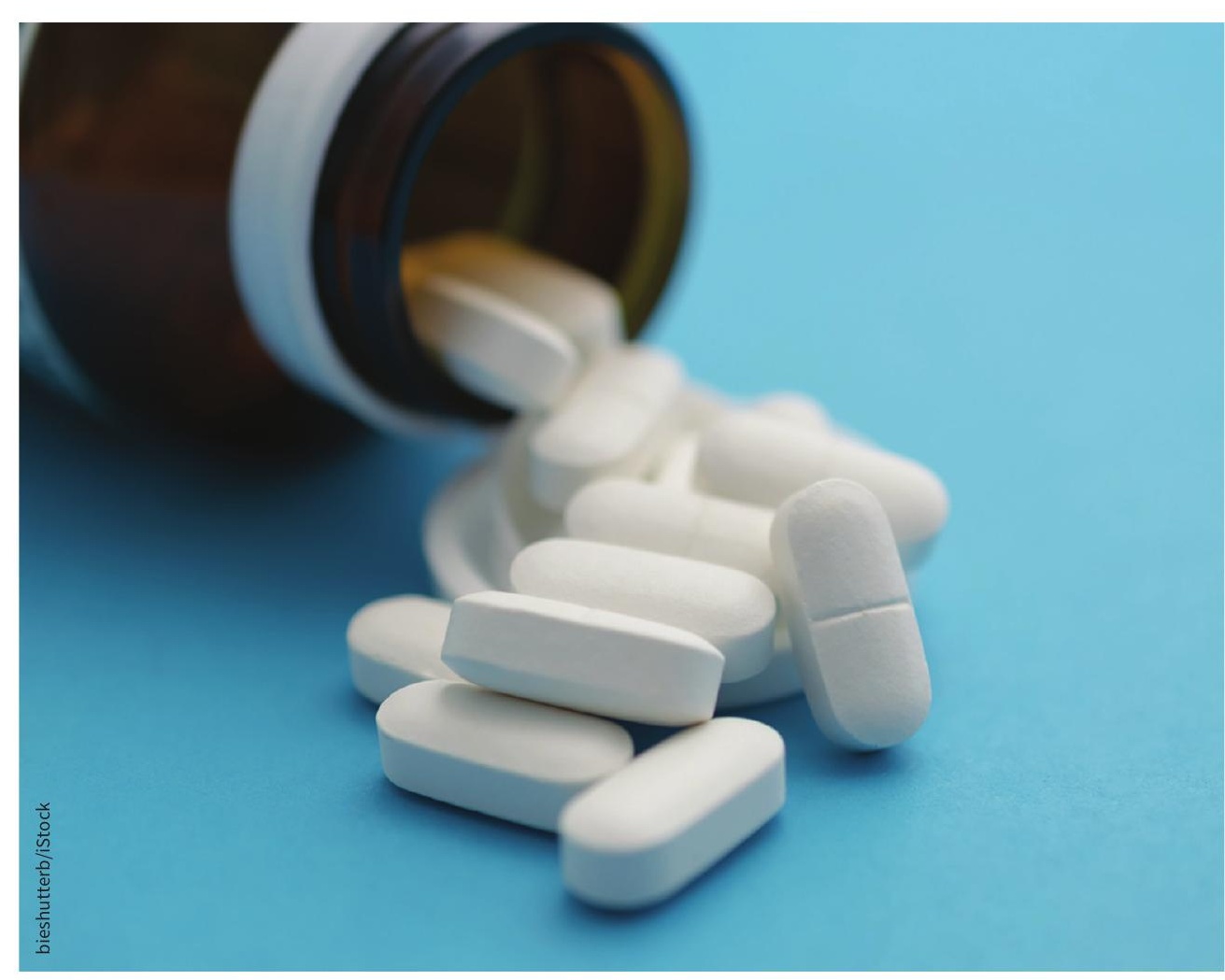

Good patient care and cutting inappropriate prescribing are not conflicting goals. mented linking BZD-use to driver's licence renewal. Long-time users of BZD with a half-life of greater than 10 hours cannot renew their driver's licence. Patients taking BZD with a half-life of exactly 10 hours must renew their licence every year, which means a test of their cognitive function.

"This is highly motivating for older people who want to remain independent, to reduce the use of the benzodiazepine," said Shaw. Between 2003 and 2013, this policy resulted in a $66 \%$ decrease in prescriptions for long-acting BZD, and a 37\% decrease in short-acting.

The policy worked because it combined changes to existing policy and guidelines for health providers as well as 
effective communication with physicians, said Shaw.

Not all public policy measures have been equally successful. France offered general practitioners a 5000 Euro incentive to reduce prescriptions of BZD. In 2011 and 2012, there was no change. "The incentive wasn't sufficient," said Shaw.

In 2014, Australia restricted prescriptions of alprazolam, which was deemed a more toxic BZD. The result was a $22 \%$ decrease in prescribing, but an increasing percentage of patients on alprazolam then switched to other BZD (a $216 \%$ increase), antidepressants (142\%) and antipsychotics (129\%). There was a $50 \%$ decrease in calls to the poison call centre - a sought-for outcome - but between 2009 and 2015, overdose deaths from BZDs increased from $42 \%$ to $52 \%$.

"We want to bring best evidence to the process, but we also need to be relentless in understanding what else is going on and the unintended consequences of our actions," said Shaw.

Geriatrician Dr. James Silvius, the cofounder of CaDeN, acknowledged that policy change is hard because people perceive it as taking something away. The public needs to understand what the change is about, he stressed, otherwise "governments may be pressured into going in another direction."

Among respondents to a new CaDeN survey of 26665 Canadians age 65 or older who live in their homes, only $7 \%$ knew what deprescribing was. Yet, 95\% had taken medicine in the last 12 months. About a third of respondents said they had stopped taking drugs because they wanted to, without talking to anyone.

The cost of adverse effects needs to be addressed, said session moderator Marnie Mitchell of Health Canada. "What are these drugs really doing when we get large numbers of people on them," she asked, citing as an example, adverse effects such as Clostridium difficile infection, pneumonia and bone density issues from proton-pump inhibitors She concluded that more thought needs to be devoted to what happens after drugs are approved.

Barbara Sibbald, CMAJ 